\title{
CONTINUOUS-FLOW ELECTROPHORESIS FOR CONCENTRATION OF PROTEIN
}

\author{
SHUANG NING ZHENG, TOSHIKUNI YONEMOTO \\ AND TEIRIKI TADAKI \\ Department of Biochemistry and Engineering, Tohoku University, \\ Sendai 980
}

Key Words: Biochemical Engineering, Electrophoresis, Transport Equation, Protein, Numerical Simulation

\begin{abstract}
A mathematical model suitable for a continuous electrophoretic concentration of protein is presented. The model equation was solved by using a finite-difference numerical method with an upwind-difference scheme. A stable and satisfactory numerical result was obtained. The experimental results quantitatively, or at least qualitatively, agree with the theoretical predication, indicating that the mathematical model and numerical method are valid.

The effect of various operating factors including the buffers added to the feed solution and the composition of the electrode solution has been analyzed on the basis of the experimental results and theoretical predications. The result indicates that the degree of concentration of protein depends on the $\mathrm{pH}$ distribution in the electrophoretic chamber. The $\mathrm{pH}$ distribution is affected not only by the kinds of buffers added to the feed solution but also by the composition of the electrode solutions.
\end{abstract}

\section{Introduction}

As is well known, most biochemical compounds are, by nature, amphoteric. An ampholyte will be positively charged at low $\mathrm{pH}$, and negatively charged at high $\mathrm{pH}$. Each ampholyte has an inherent isoelectric point at an intermediate $\mathrm{pH}$ where net charge is zero, and also has different electrophoretic velocity depending on the $\mathrm{pH}$ of surrounding media. These physical properties have, for a long time, allowed

\footnotetext{
* Received February 6, 1990. Correspondence concerning this article should be addressed to T. Tadaki.
}

utilization of electrophoretic techniques in the analytical chemistry field for the identification and purification of biochemical compounds.

Chemical engineers have paid attention to the scale up of the apparatus from those of analytical scale to those for use in industrial separation during the last few decades. ${ }^{3,4,7,10,18,19)}$

Some efforts have been made to establish a theoretical model of the electrophoretic process. ${ }^{1,3,13)}$ The present authors ${ }^{20,21)}$ have also provided a mathematical model and a numerical technique to analyze a continuously concentrating and separating 
process of amino acids under the constant voltage condition. This paper has extended our previous work on continuous flow electrophoresis to the concentration process of protein. The validity of the theoretical analysis was ascertained by comparison with experimental data, and the effects of operating factors on the electrophoretic concentration of protein were discussed.

\section{Theory}

\subsection{Dissociation of ampholytes}

Protein is a kind of amphoteric macromolecule. It can exist in various charged states, due to the association-dissociation reaction with hydrogen ions in aqueous solution.

There are only $\alpha$-amino, $\varepsilon$-amino, imidazole, and guanidine dissociable basic groups, and $\alpha$-carboxyl, $\beta$-carboxyl, $\gamma$-carboxyl, sulfhydryl, and phenol acidic groups in the usual protein. Utilizing the concept of so-called intrinsic dissociation constants, and also taking into account the electrostatic interaction of the Linderstrøm-Lang type, a net average charge and a mean square charge for the protein can be written respectively as ${ }^{16)}$

$$
\begin{gathered}
\tilde{n}=\sum_{\mathrm{i}=1}^{4} \frac{N_{i}[H]}{K_{i} \exp (2 \omega \cdot \tilde{n})+[H]}-\sum_{\mathrm{j}=1}^{5} \frac{N_{j} K_{j} \exp (2 \omega \cdot \tilde{n})}{K_{j} \exp (2 \omega \cdot \tilde{n})+[H]} \\
\widetilde{n^{2}}=(\tilde{n})^{2}+\sum_{\mathrm{i}=1}^{4} \frac{N_{i} K_{i}[H] \exp (2 \omega \cdot \tilde{n})}{\left(K_{i} \exp (2 \omega \cdot \tilde{n})+[H]\right)^{2}} \\
+\sum_{\mathrm{j}=1}^{5} \frac{N_{j} K_{j}[H] \exp (2 \omega \cdot \tilde{n})}{\left(K_{j} \exp (2 \omega \cdot \tilde{n})+[H]\right)^{2}}
\end{gathered}
$$

where $K_{i}$ and $N_{i}$ are the intrinsic dissociation constant and the number of the dissociable basic groups, and $K_{j}$ and $N_{j}$ are those of the acidic groups. $\omega$ is a function of the physical dimension of the protein molecule and the ionic strength of the surrounding solution. One may calculate $\omega$ according to the following equation, at $298 \mathrm{~K}$,

$$
\omega=3.6 \times 10^{-10}\left(\frac{1}{b}-\frac{3.3 \times 10^{9} \sqrt{I}}{1+3.3 \times 10^{9} a \cdot \sqrt{I}}\right)
$$

where $a$ is the exclusion radius, $b$ is the protein molecule radius, and $I$ is ionic strength.

Amino acid, which serves as a buffer reagent, is also an ampholyte. The number of dissociable acidic or basic groups for most amino acids is not more than two; hence, the equilibria of the dissociation reaction of amino acid can be expressed by

$$
\begin{gathered}
{\left[A^{+}\right] /\left[A^{2+}\right]=K_{A 1} /[H]} \\
{\left[A^{0}\right] /\left[A^{+}\right]=K_{A 2} /[H]} \\
{\left[A^{-}\right] /\left[A^{0}\right]=K_{A 3} /[H]}
\end{gathered}
$$

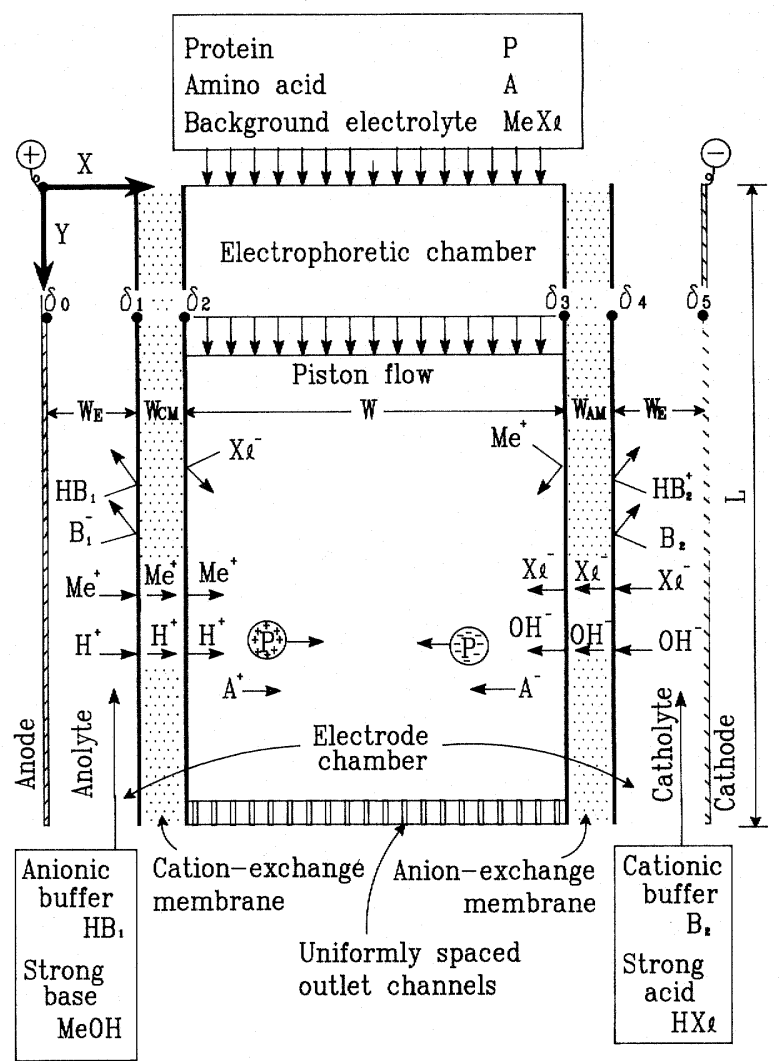

Fig. 1. Schematic representation of continuous electrophoretic system

$$
\left[A^{2-}\right] /\left[A^{-}\right]=K_{A 4} /[H]
$$

The equilibrium of the dissociation reaction of water can then be expressed by

$$
K_{W}=[H][O H]
$$

\subsection{Transport equations}

The continuous flow electrophoretic process is schematically shown in Fig. 1. The electrophoretic chamber is a vertical rectangular, thin-slit flow cell. An aqueous protein solution with amino acids and background electrolyte (MeX $\boldsymbol{\ell})$ is uniformly fed from the top of the chamber. Anolyte, an aqueous solution of a strong base (MeOH) and anionic buffer $\left(\mathbf{H B}_{1}\right)^{*}$, is fed into the anodic chamber separated from the electrophoretic chamber by a cation-exchange membrane. Catholyte, an aqueous solution of strong acid (HX $\boldsymbol{\ell}$ ) and cationic buffer $\left(\mathbf{B}_{2}\right)$, is fed into the cathodic chamber separated from the electrophoretic chamber by an anion-exchange membrane.

When a potential difference is applied between the two electrodes, all cationic species including $\mathbf{H}^{+}$will permeate the cation-exchange membrane from the

* A mild pH distribution in the electrophoretic chamber is desired for prevention of denaturation of protein. Therefore, we have used the buffer as electrode solution here, rather than strong acid and base as used in the previous papers about concentration and separation of amino acids. ${ }^{20,21)}$ 
anodic chamber, and all anionic species including $\mathbf{O H}^{-}$will permeate the anion-exchange membrane from the cathodic chamber, to enter the electrophoretic chamber. Consequently, a $\mathrm{pH}$ gradient will form in the electrophoretic chamber.

With the $\mathrm{pH}$ and potential gradients, ions will migrate and the amphoteric species such as protein and amino acids will concentrate at the positions corresponding to their respective isoelectric $\mathrm{pH}$ values. It is obvious that, in order to describe the system, transport phonemena in the membranes and the electrode chamber, together with the those in the electrophoretic chamber, must be simultaneously considered. Now assuming that, throughout the system:

1) steady state, dilute and isothermal solution,

2) constant physical properties,

3) rapidly local dissociation reaction equilibria,

in the electrophoretic chamber:

4) piston flow along the $Y$ direction,

5) negligibly small dispersive and migratory transports, compared with convective transport along the $Y$ direction,

in the electrode chambers:

6) the concentrations to be uniform, owing to rapid circulation of the electrode solutions

in the membrane phases:

7) Donnan equilibrium to be set up, and Donnan electric potential between the liquid and membrane to be able to neglect,

and using a cation-exchange membrane capacity $\left(Q_{C}\right)$, the electrophoretic chamber width $(W)$, and superficial convective velocity $(v)$ as characteristic concentration, length, and velocity, respectively, further assigning 1: $\mathbf{M e}^{+}, 2: \mathbf{X} \boldsymbol{\ell}^{-}, 3: \mathbf{H}^{+}, 4: \mathbf{O H}^{-}, 5:$ $\mathbf{A}_{1}^{2+}, 6: \mathbf{A}_{1}^{+}, 7: \mathbf{A}_{1}^{0}, 8: \mathbf{A}_{1}^{-}, 9: \mathbf{A}_{1}^{2-}, \cdots, 5 \mathrm{M}: \mathbf{A}_{\mathrm{M}}^{2+}$, $5 \mathrm{M}+1: \mathbf{A}_{\mathrm{M}}^{+}, 5 \mathrm{M}+2: \mathbf{A}_{\mathrm{M}}^{0}, 5 \mathrm{M}+3: \mathbf{A}_{\mathrm{M}}^{-}, 5 \mathrm{M}+4: \mathbf{A}_{\mathrm{M}}^{2-}$, and $5 \mathrm{M}+5$ : Protein, the following equations for each species can be obtained, in the electrophoretic chamber:

mass balance equations,

$$
\begin{gathered}
\frac{n_{i}}{P e_{M_{i}}} \frac{\partial}{\partial X}\left(Z_{i} \frac{\partial \Phi}{\partial X}\right)+\frac{1}{P e_{D_{i}}} \frac{\partial^{2}}{\partial X^{2}}-\frac{\partial Z_{i}}{\partial Y}=0 \quad \mathrm{i}=1-2 \\
\sum_{\mathrm{i}=5 \mathrm{~m}}^{5 \mathrm{~m}+4}\left\{\frac{n_{i}}{P e_{M_{i}}} \frac{\partial}{\partial X}\left(Z_{i} \frac{\partial \Phi}{\partial X}\right)+\frac{1}{P e_{D_{i}}} \frac{\partial^{2} Z_{i}}{\partial X^{2}}-\frac{\partial Z_{i}}{\partial Y}\right\}=0 \\
\frac{\mathrm{m}=1,2, \cdots \mathrm{M}}{P e_{M_{i}}} \frac{\partial}{\partial X}\left(\tilde{n} Z_{i} \frac{\partial \Phi}{\partial X}\right)+\frac{1}{P e_{D_{i}}} \frac{\partial^{2} Z_{i}}{\partial X^{2}}-\frac{\partial Z_{i}}{\partial Y}=0 \quad \mathrm{i}=5 \mathrm{M}+5
\end{gathered}
$$

charge balance equation,

$$
\begin{gathered}
\sum_{\mathrm{i}=1}^{5 \mathrm{M}+4}\left\{\frac{1}{P e_{M_{i}}} \frac{\partial}{\partial X}\left(n_{i}^{2} Z_{i} \frac{\partial \Phi}{\partial X}\right)+\frac{1}{P e_{D_{i}}} \frac{\partial^{2}\left(n_{i} Z_{i}\right)}{\partial X^{2}}\right\} \\
+\frac{1}{P e_{\mathrm{M}_{5 \mathrm{M}+5}}} \frac{\partial}{\partial X}\left(\widetilde{n^{2}} Z_{5 \mathrm{M}}+\frac{\partial \Phi}{\partial X}\right) \\
+\frac{1}{P e_{D_{5 \mathrm{M}+5}}} \frac{\partial^{2}\left(\tilde{n} Z_{5 \mathrm{M}+5}\right)}{\partial X^{2}}=0
\end{gathered}
$$

electroneutral condition,

$$
\sum_{i=1}^{5 \mathrm{M}+4} n_{i} Z_{i}+\tilde{n} Z_{5 \mathrm{M}+5}=0
$$

initial condition,

$$
Y=0 ; \quad Z_{i}=Z_{i, \text { in }}
$$

in the ion-exchange membranes:

mass balance equation' (see appendix),

$$
\begin{aligned}
\bar{Z}_{i}= & \left(\left.\bar{Z}_{i}\right|_{\delta_{j+1}}-\left.\bar{Z}_{i}\right|_{\delta_{j}}\right) \frac{\exp \left\{-n_{i} \bar{E}\left(X-X_{\delta_{j}}\right)\right\}}{\exp \left\{-n_{i} \bar{E}\left(X_{\delta_{j+1}}-X_{\delta_{j}}\right)\right\}-1} \\
& +\left.\bar{Z}_{i}\right|_{\delta_{j}} \\
& \mathrm{i}=1, \mathrm{j}=1 \text { for cation-exchange membrane } \\
& \mathrm{i}=2, \mathrm{j}=3 \text { for anion-exchange membrane }
\end{aligned}
$$

charge balance equation,

$$
\begin{aligned}
\left(\frac{n_{i}^{2} \bar{E}}{\overline{P e}_{i}} \frac{\partial \bar{Z}_{i}}{\partial X}+\frac{n_{i}}{\overline{P e}_{i}} \frac{\partial^{2} \bar{Z}_{i}}{\partial X^{2}}\right) & \\
+( & \left(\frac{n_{i+2}^{2}}{\overline{P e}_{i+2}} \frac{\partial \bar{Z}_{i+2}}{\partial X}+\frac{n_{i+2}}{\overline{P e}_{i+2}} \frac{\partial^{2} \bar{Z}_{i+2}}{\partial X^{2}}\right)=0 \\
\quad \mathrm{i} & =1, \text { for cation-exchange membrane } \\
\quad \mathrm{i} & =2, \text { for anion-exchange membrane, }
\end{aligned}
$$

electroneutral condition,

$$
\bar{Z}_{i}+\bar{Z}_{i+2}=Q
$$

$\mathrm{i}=1, Q=1$ for cation-exchange membrane

$\mathrm{i}=2, Q=Q_{A} / Q_{C}$ for anion-exchange membrane

in the electrode chambers:

charge balance equation,

$$
\partial^{2} \Phi / \partial X^{2}=0
$$

concentration condition,

$$
Z_{i}=\text { const. }
$$

boundary conditions:

at the anode,

$$
X=X_{\delta_{0}} ; \quad \Phi=\Phi_{0},
$$

at the cation-exchange membrane,

$$
\begin{aligned}
& X=X_{\delta_{1}} \text { or } X_{\delta_{2}} ; \bar{K}_{C M}=\left(\bar{Z}_{1} / \bar{Z}_{3}\right)\left(Z_{3} / Z_{1}\right) \\
& \bar{K}_{C M}=\exp \left(A_{C M}-B_{C M} \frac{Z_{1}}{Z_{1}+Z_{3}}\right) \\
& \bar{\Phi}=\Phi
\end{aligned}
$$




$$
\begin{array}{ll}
\bar{N}_{\mathrm{i}}=\mathscr{N}_{\mathrm{i}} & \mathrm{i}=1,3 \\
\bar{N}_{\mathrm{i}}=\mathscr{N}_{\mathrm{i}}=0 & \mathrm{i} \neq 1,3
\end{array}
$$

at the anion-exchange membrane,

$$
\begin{aligned}
X=X_{\delta_{3}} \text { or } X_{\delta_{4}} ; & \bar{K}_{A M}=\left(\bar{Z}_{2} / \bar{Z}_{4}\right)\left(Z_{4} / Z_{2}\right), \\
& \bar{K}_{A M}=\exp \left(A_{A M}-B_{A M} \frac{Z_{2}}{Z_{2}+Z_{4}}\right) \\
& \bar{\Phi}=\Phi \\
& \bar{N}_{\mathrm{i}}=\mathscr{N}_{\mathrm{i}}, \quad \mathrm{i}=2,4 \\
& \bar{N}_{\mathrm{i}}=\mathscr{N}_{\mathrm{i}}=0 \quad \mathrm{i} \neq 2,4
\end{aligned}
$$

at the cathode,

$$
X=X_{\delta_{5}} ; \quad \Phi=0
$$

where $\bar{K}_{C M}$ and $\bar{K}_{A M}$ are selectivity coefficients for membranes, and $A_{C M}, B_{C M}, A_{A M}, B_{A M}$ are constants. These formulas, combined with Eqs. (1)-(5), are a set of governing equations. The equations can be solved by using the finite-difference numerical procedure presented in our previous paper. ${ }^{20)}$

\section{Experimental}

\subsection{Apparatus and procedure}

The electrophoretic apparatus used in the experiments is the same as that in the previous work. ${ }^{20)}$

Bovine serum albumin (BSA) was used as model protein, glutamic acid (Glu), histidine (His) and arginine (Arg) as buffers, $\mathbf{K C l}$ as background electrolyte. Albumin concentrations in the samples were quantitatively determined at $280 \mathrm{~nm}$ by a UV spectrophotometer. $\mathrm{pH}$ was also detected by a $\mathrm{pH}$ meter.

In addition, succinic acid and $\mathbf{K O H}$ served as the anolyte and Tris and $\mathbf{H C l}$ as the catholyte.

All experiments were conducted at $298 \mathrm{~K}$.

\subsection{Physical properties}

The number of dissociable side-chain acidic or basic groups and their intrinsic dissociation constants for the protein are listed in Table 1. ${ }^{17)}$

Isoelectric points of each ampholyte and dissociation constants of species are listed in Table $2 .{ }^{5)}$

Diffusion coefficients in the aqueous solution are listed in Table 3. ${ }^{6,8,12)}$ The method of estimation for diffusion coefficients and dispersion coefficents was the same as in our previous paper. ${ }^{20,21)}$ The values of diffusion coefficients for glutamic acid and arginine were estimated by the Wilke-Chang empirical correlation. ${ }^{11)}$

The effective diffusion coefficients of species within the membranes, together with the membrane's

\begin{tabular}{|c|c|c|c|c|c|c|}
\hline \multirow{2}{*}{ Species } & \multicolumn{5}{|c|}{$p K(=-\log K)$} & \multirow[t]{2}{*}{$p I$} \\
\hline & $(2+) \rightleftharpoons$ & $(+) \rightleftharpoons$ & $(0) \rightleftharpoons$ & $(-)$ & $\rightleftharpoons(-2)$ & \\
\hline BSA & & & & & & $5.10^{*}$ \\
\hline Glu & - & 2.10 & 4.07 & & 9.47 & 3.09 \\
\hline His & 1.82 & 6.04 & 9.12 & & - & 7.58 \\
\hline Arg & 2.02 & 9.04 & 12.48 & & - & 10.76 \\
\hline Succinic acid & - & - & 4.16 & & 5.61 & \\
\hline Tris & - & 8.06 & - & & - & \\
\hline Piperazine & - & 9.81 & - & & - & \\
\hline $\mathrm{H}_{2} \mathrm{O}$ & - & - & 13.99 & & - & \\
\hline
\end{tabular}
equilibrium data and the membrane capacity, are listed in Table 4. ${ }^{14)}$
Table 1. Dissociable side-chain groups and their intrinsic dissociation constants for BSA

\begin{tabular}{rlrr}
\hline $\mathrm{i}$ & Group & $N_{\mathrm{i}}$ & $p K_{\mathrm{i}}$ \\
\hline 1 & $\alpha$-Amino & 1 & 7.75 \\
2 & $\varepsilon$-Amino & 57 & 9.80 \\
3 & Imidazole & 16 & 6.90 \\
4 & Guanidine & 22 & 12.00 \\
\hline $\mathrm{j}$ & Group & $N_{\mathrm{j}}$ & $p K_{\mathrm{j}}$ \\
\hline 1 & $\alpha$-Carboxyl & 1 & 3.75 \\
2 & $\beta$-Carboxyl & 99 & 3.95 \\
3 & $\gamma$-Carboxyl & & \\
4 & Sulfhydryl & 0 & - \\
5 & Phenolic & 19 & 10.35 \\
\hline
\end{tabular}

Table 2. Dissociation constants and isoelectric points in aqueous solution at $298 \mathrm{~K}$

* Calculated value by using Eq. (1)

Table 3. Diffusion coefficients in aqueous solution at $298 \mathrm{~K}$

\begin{tabular}{lc}
\hline \multicolumn{1}{c}{ Species } & Diffusion coef. $\left[\mathrm{m}^{2} \cdot \mathrm{s}^{-1}\right]$ \\
\hline $\mathbf{K}^{+}$ & $1.956 \times 10^{-9}$ \\
$\mathbf{C l}^{-}$ & $2.032 \times 10^{-9}$ \\
$\mathbf{H}^{+}$ & $9.310 \times 10^{-9}$ \\
$\mathbf{O H}^{-}$ & $5.277 \times 10^{-9}$ \\
$\mathbf{G l u}$ & $8.484 \times 10^{-10}$ \\
His & $7.328 \times 10^{-10}$ \\
Arg & $7.139 \times 10^{-10}$ \\
$\mathbf{B S A}$ & $6.102 \times 10^{-11}$ \\
Succinic acid & $9.990 \times 10^{-10}$ \\
Tris & $9.010 \times 10^{-10}$ \\
Piperazine & $1.038 \times 10^{-9}$ \\
\hline
\end{tabular}

Table 4. Diffusion coefficients in the membranes, membrane capacities and constants in the selectivity coefficient correlation, at $298 \mathrm{~K}$

\begin{tabular}{lccc}
\hline Species & $\begin{array}{c}\text { Diffusion coef. } \\
\mathrm{m}^{2} \cdot \mathrm{s}^{-1}\end{array}$ & $\begin{array}{c}\text { Memb. capacity } \\
\text { eq. } \cdot \mathrm{m}^{-3}\end{array}$ & const. \\
\hline $\mathbf{K}^{+}$ & $1.200 \times 10^{-10}$ & $2.100 \times 10^{3}$ & $A_{C M}=1.110$ \\
$\mathbf{H}^{+}$ & $4.500 \times 10^{-10}$ & & $B_{C M}=1.060$ \\
$\mathbf{C l}^{-}$ & $2.480 \times 10^{-11}$ & $1.520 \times 10^{3}$ & $\begin{array}{l}A_{A M}=3.308 \\
\mathbf{O H}^{-}\end{array}$ \\
\hline
\end{tabular}




\section{Results and discussion}

Figure 2 shows the evolution of the distributions of protein, pH, buffer (Glu, His), and background electrolyte $\left(\mathbf{K}^{+}\right.$and $\left.\mathbf{C l}^{-}\right)$at different positions along the $Y$-axis $(y / L=0.1,0.5$, and 1.0). The abscissa represents the dimensionless $X$ axis, and the ordinates represent the dimensionless concentrations of the species and $\mathrm{pH}$.

The small concentration peak of the protein near the cation-exchange membrane is first formed at the small $X$ and the peak gradually moves toward the central part in the electrophoretic chamber during the course of the downward flow, while migration of the protein near the anion-exchange membrane was not obvious (see Fig. 2(A)). It seems reasonable to relate this fact to the $\mathrm{pH}$ distribution shown in the following Fig. 2(B), because the net charge of the protein depends largely on $\mathrm{pH}$ (see Eq. (1)). It can be observed from the figure that the $\mathrm{pH}$ gradient was initially formed at the positions near the membranes and extended gradually toward the center, with increase of $Y$. Since permeability of the $\mathbf{O H}^{-}$for the anion-exchange membrane is far less than that of $\mathbf{H}^{+}$for the cation-exchange membrane*, the change of the $\mathrm{pH}$ near the anion-exchange membrane is not obvious, compared to that near the cation-exchange membrane. Corresponding to the $\mathrm{pH}$ distribution formed, the protein does not significantly migrate at the side of the anion-exchange membrane.

On the other hand, glutamic acid and histidine are acidic and basic amino acids, respectively. They will migrate toward the anodic and cathodic sides, and concentrate near the membranes, respectively. It is expected that they can buffer $\mathrm{pH}$ there, and play an important role in the concentration of the protein.

The experimental protein concentration and $\mathrm{pH}$, together with the corresponding theoretical results of the Fig. 2, are shown in Fig. 3. In the figure, theoretical results are integral average ones with respect to each outlet width, for comparison to the experimental results. It can be found that the experimental results were in fair agreement with the theoretical ones, indicating that the mathematical model and the numerical method are mostly valid.

Figure 4 shows the effect of the electrode solution on the $\mathrm{pH}$ and the protein concentration distribution in the electrophoretic chamber. Here, we adjusted the $\mathrm{pH}$ of the anolyte to 3.7 , and the $\mathrm{pH}$ of the catholyte to 9 . Comparing with that of Fig. 3, it can be seen that the $\mathrm{pH}$ near the cation-exchange membrane increase with increasing $\mathrm{pH}$ of the anolyte, and

$* \mathbf{H}^{+}\left(\mathbf{K}^{+}\right)$occupied $10 \% \quad(90 \%)$ of the capacity of the cation-exchange membrane, as can be seen from Fig. 2(E), while $\mathbf{O H}^{-}$occupied only about $1 \%\left(\mathrm{Cl}^{-}\right.$above $\left.99 \%\right)$, from Fig. 2(F). This suggests that the mass flux of $\mathbf{O H}^{-}$is relatively small.
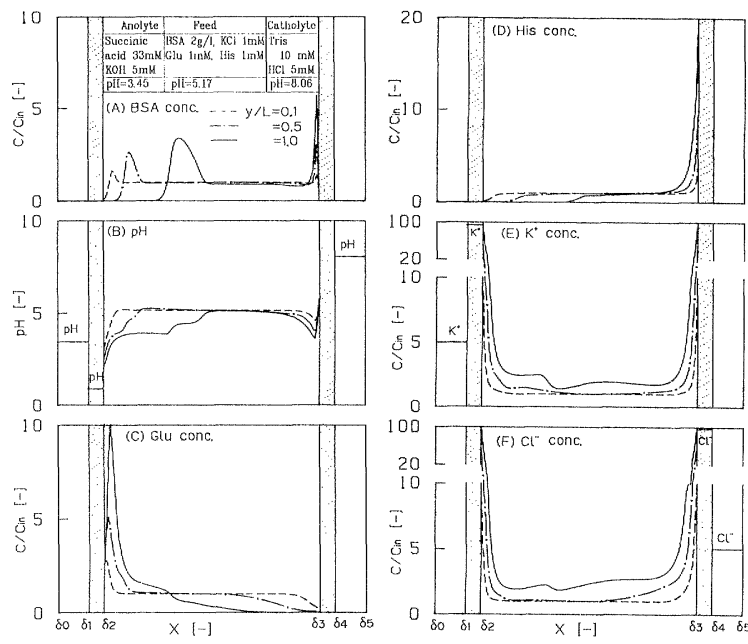

Fig. 2. Continuous electrophoretic concentration behavior of bovine serum albumin for $\Delta V=300 \mathrm{~V}, \tau=1000 \mathrm{~s}$, at $y / L=0.1,0.5$ and 1.0

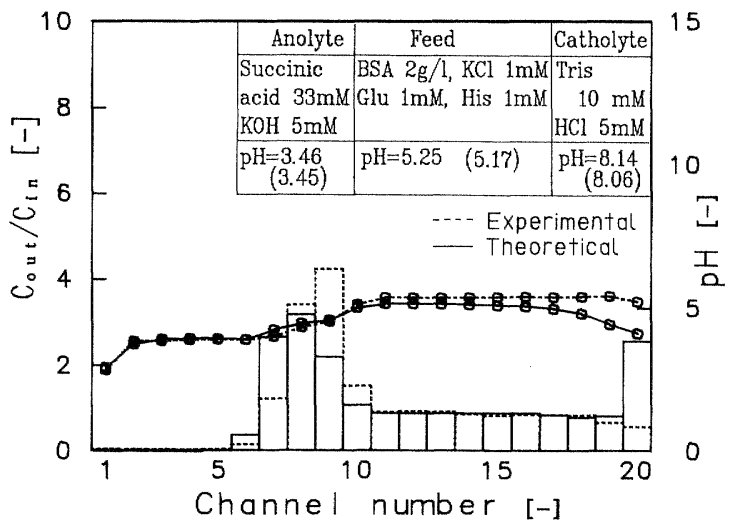

Fig. 3. Comparison of experimental result and theoretical predication for continuous electrophoretic concentration of bovine serum albumin

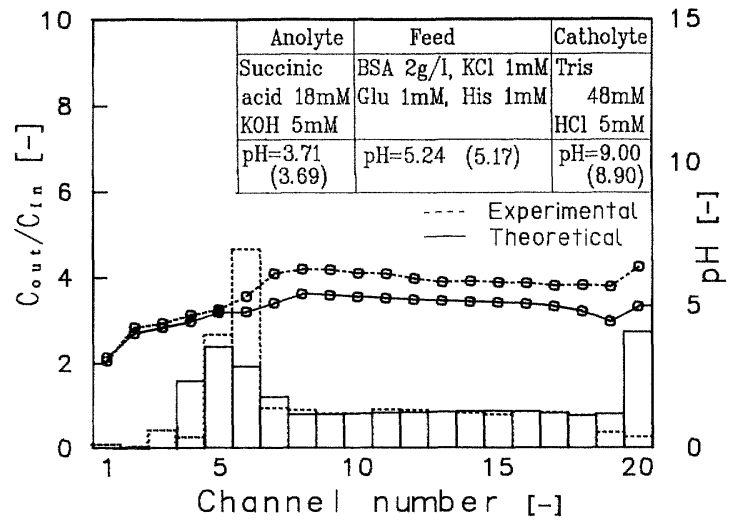

Fig. 4. Effect of electrode solution on concentration of bovine serum albumin, corresponding to $\Delta V=300 \mathrm{~V}$, $\tau=1000 \mathrm{~s}$. Here, electrode solutions are different from Fig. 3

consequently, the protein concentration peak also shift toward the cation-exchange membrane. On the contrary, the $\mathrm{pH}$ near the anion-exchange membrane dose not obviously change, and the protein in the 


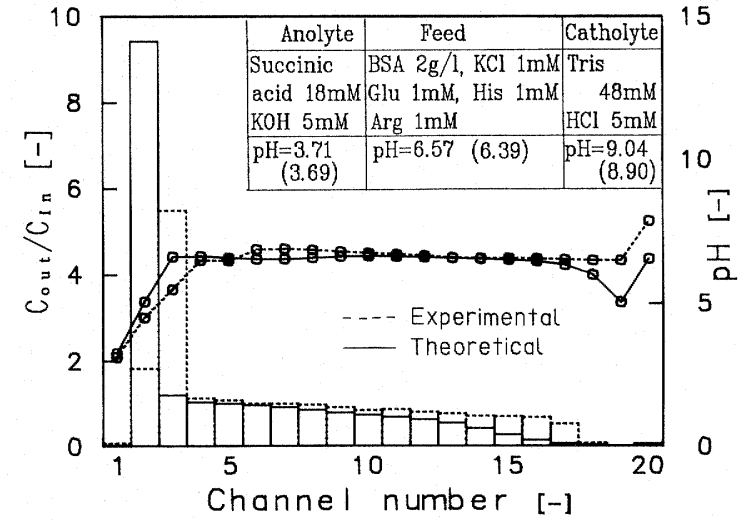

Fig. 5. Effect of buffer in feed solution on concentration of bovine serum albumin, corresponding to $\Delta V=300 \mathrm{~V}$, $\tau=1000 \mathrm{~s}$. Here, except for composition of feed, other conditions are the same as in Fig. 4

region is not significantly concentrated although the $\mathrm{pH}$ is adjusted to 9 . This suggests that the permeativity of $\mathrm{OH}^{-}$for the anion-exchange membrane does not significantly change with $\mathrm{pH}$ of the catholyte.

The effect of buffer species in the feed solution on the degree of concentration of the protein and $\mathrm{pH}$ is shown in Fig. 5. Here, the $\mathrm{pH}$ of the feed solution was adjusted to 6.5 by adding arginine, a basic amino acid, to the feed. By comparison with Fig. 4, it can be seen that not only the protein concentration peak shift toward the cation-exchange membrane, but its degree of concentration increases. It may be thought that because the protein near the anion-exchange membrane is more negatively charged by adjustment of $\mathrm{pH}$ to higher than the isoelectric point of the protein, it migrates more easily.

From the above comparison, we can find that most of the theoretical predications are in fairly good agreement with those of the experiments, but some disagreements, espacially at the vicinity of the ion-exchange membranes, also exist. These disagreements may be attributed to the boundary condition adopted in our calculation. We have assumed that Donnan equilibrium is always set up at the interface between the membrane and liquid. Perhaps, the assumption is incomplete, and causes a deviation of concentration distribution of respective species from actual one.

\section{Conclusions}

A methematical model and numerical method, suitable for the continuous electrophoretic concentration of proteins have been developed on the basis of transport equations including dissociation reaction equilibria. The validity of the mathematical model and the numerical method have been, quantitatively, or at least qualitatively, verified by the comparison of the experimental results with the theoretical ones. Some disagreements may be atrributed to the boundary conditions adopted.

Either the theoretical prediction or the experimental results show that the degree of concentration of the protein depends on the buffer of the feed solution and of the electrode solution, because $\mathrm{pH}$ distribution in the electrophoretic chamber depends on these buffers.

\section{Acknowledgements}

The authors would like to thank Mr. K. Hori and Mr. T. Hoshi for their assistance in part of the experimental work of this study.

\section{Appendix}

The mass balance equation for $\mathbf{K}^{+}$, for example in the cation-exchange membrane, and corresponding boundary conditions can be written as

$$
\begin{gathered}
\frac{n_{1} \bar{E}}{P e_{1}} \frac{\partial \bar{Z}_{1}}{\partial X}+\frac{1}{P e_{1}} \frac{\partial \bar{Z}_{1}}{\partial X^{2}}=0 \\
X=X_{\delta_{1}}: \quad \bar{Z}_{1}=\left.\bar{Z}_{1}\right|_{\delta_{1}} \\
X=X_{\delta_{2}}: \quad \bar{Z}_{1}=\left.\bar{Z}_{1}\right|_{\delta_{2}}
\end{gathered}
$$

Eq. (A-1) is linear differential equation with constant coefficients, and the solution is

$$
\bar{Z}_{1}=C_{1} \exp \left(-n_{1} \bar{E} X\right)+C_{2}
$$

where, $C_{1}$ and $C_{2}$ are arbitrary constants.

Substituting Eqs. (A-2) and (A-3) into Eq. (A-4), and rearranging the equation give Eq. (12).

\section{Nomenclature}

$A \quad=$ constant in Eq. (17) $\quad[-]$

$a \quad=$ exclusion radius which represents a distance of closest approach of salt ions $\left(a=b+2.5 \times 10^{-10}\right)$

$B \quad=$ constant in Eq. (17) $\quad[-]$

$b \quad=$ radius of protein molecule $\quad[\mathrm{m}]$

C $=$ concentration $\left[\mathrm{mol} \cdot \mathrm{m}^{-3}\right]$

$\bar{C} \quad=$ concentration in the membranes $\quad\left[\mathrm{mol} \cdot \mathrm{m}^{-3}\right]$

$C_{\text {in }} \quad=$ total concentration at inlet $\quad\left[\mathrm{mol} \cdot \mathrm{m}^{-3}\right]$

$C_{\text {out }} \quad=$ total concentration at outlet $\quad\left[\mathrm{mol} \cdot \mathrm{m}^{-3}\right]$

$D \quad=$ molecular diffusion coefficient $\left[\mathrm{m}^{2} \cdot \mathrm{s}^{-1}\right]$

$\bar{D}=$ diffusion coefficient for the membranes

$E \quad=$ dispersion coefficient

$\bar{E} \quad=$ electric field in the membrane

$F \quad=$ Faraday's constant

$I \quad=$ ionic strength $\left(=1 / 2 \Sigma n_{i}^{2} Z_{i} / 1000\right)$ $\left[\mathrm{m}^{2} \cdot \mathrm{s}^{-1}\right]$ $\left[\mathrm{m}^{2} \cdot \mathrm{s}^{-1}\right]$ $[-]$ $\left[\mathrm{A} \cdot \mathrm{s} \cdot \mathrm{mol}^{-1}\right]$

$\left[\mathrm{mol} \cdot \mathrm{m}^{-3}\right]$

$\bar{K} \quad=$ selectivity coefficient defined by Eq. (17) $\quad[-]$

$K_{A} \quad=$ dissociation constant of amino acids $\quad[-]$

$K_{w} \quad=$ dissociation constant of water $\quad[-]$

$K_{i}, K_{j} \quad=$ intrinsic dissociation constants for dissociable side-chain basic and acidic groups of protein, respectively $\quad[-]$

$L=$ chamber height (see Fig. 1) [m]

$\begin{aligned} N_{i}, N_{j}= & \text { the number of dissociable side-chain } \\ & \text { basic and acidic groups of protein }\end{aligned}$

$N \quad=$ mass flux vector $\left[\mathrm{mol} \cdot \mathrm{m}^{-2} \cdot \mathrm{s}^{-1}\right]$

$\mathscr{N} \quad=$ dimensionless mass flux vector, $N \varepsilon / v Q_{C} \quad[-]$

$n \quad=$ valence $\quad[-]$

$\tilde{n} \quad=$ net charge of protein $\quad[-]$

$\widetilde{n^{2}} \quad=$ mean square charge of protein $\quad[-]$

$\overline{P e} \quad=$ Peclet number for the membrane, $v W / \bar{D} \quad[-]$

$P e_{D} \quad=$ dispersion peclet number, $v W / E \varepsilon \quad[-]$ 


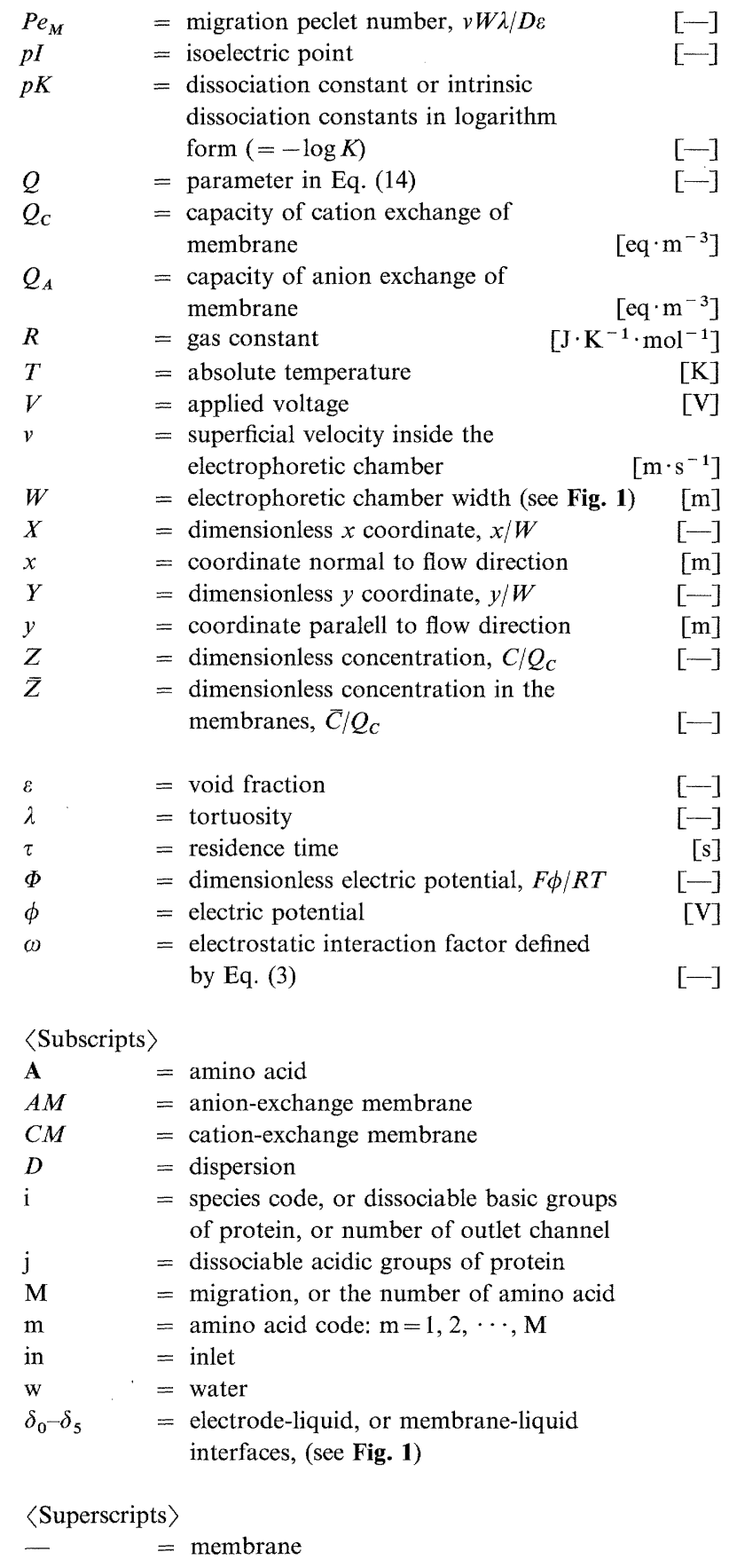

,,$+- 0=$ cationic, anionic and neutral species,

\section{Literature Cited}

1) Beckwith, J. B. and C. F. Ivory: Chem. Eng. Comm., 54, 301 (1987).

2) Bier, M., R. A. Mosher and O. A. Palusinski: J. Chromatogr., 211, 313 (1981).

3) Gobie, W. A. and C. F. Ivory: AIChE J., 34, 474 (1988).

4) Hannig, K.: Z. Anal. Chem., 181, 244 (1961).

5) Kortum, G., W. Vogel and K. Andruss, Dissociation Constants of Organic Acids in Aqueous Solution, p. 329-332, Butterworths Pub., London (1961).

6) Longsworth, L. G.: J. Am. Chem. Soc., 75, 5705 (1953).

7) Mattock, P., G. F. Aitchison and A. R. Thomson: Sep. Puri. Methods, 9, 1 (1980).

8) Newman, J. S., Electrochemical Systems, p. 229, Prentice-Hall, Inc., Englewood Cliffs, N. J. (1973).

9) Palusinski, O. A., A. Graham, R. A. Mosher, M. Bier and D. A. Saville: AIChE J., 32, 215 (1986).

10) Philpot, J. St. L.: Trans. Faraday Soc., 36, 38 (1940).

11) Reid, R. C., J. M. Prausnitz and T. K. Sherwood, The Properties of Gases and Liquids," 3rd, p. 567, McGraw-Hill, New York, (1977).

12) Robinson, R. A. and R. H. Stockes, Electrolyte Solution, 2nd, p. 465, 517, 518, 544, Butterworths Pub., London, (1959).

13) Reis, J. F., E. N. Lightfoot and H. L. Lee: AIChE J., 20, 362 (1974).

14) Sato, K., T. Yonemoto and T. Tadaki: J. Mem. Sci., 53, 215 (1990).

15) Saville, D. A. and O. A. Palusinski: AIChE J., 32, 207 (1986).

16) Tanford, C., Physical Chemistry of Macromolecules, Chap. 8, John Wiley \& Sons, Inc., New York, (1961).

17) Tanford, C., S. A. Swanson and W. S. Shore: J. Am. Chem. Soc., 77, 6414 (1955).

18) Vermeulen, T., L. Nady, J. M. Krochta, E. Ravoo and D. Howery: Ind. Eng. Chem. Process Des. Develop., 10, 91 (1971).

19) Yoshisato, R. A., L. M. Korndorf, G. R. Carmichael and R. Datta: Sep. Sci. Technol., 21 (8), 727 (1986).

20) Zheng, S. N., J. H. Egocheaga, T. Sato, T. Yonemoto and T. Tadaki: J. Chem. Eng. Japan, 22, 247 (1989).

21) Zheng, S. N., T. Sato, T. Yonemoto and T. Tadaki: J. Chem. Eng. Japan, 22, 564 (1989). 